\title{
Corticosteroids, Thyrotropin-Releasing Hormone, and Antioxidant Enzymes in Preterm Lamb Lungs
}

\author{
FRANS J. WALTHER, MACHIKO IKEGAMI, DAVID WARBURTON, AND DANIEL H. POLK \\ Department of Pediatrics, King-Drew Medical Center and University of California Los Angeles School of \\ Medicine, Los Angeles, California 90059 [F.J.W.]; Harbor-UCLA Medical Center, Torrance, California 90509 \\ [M.I., D.H.P.]; and Children's Hospital of Los Angeles, University of Southern California School of Medicine,
} Los Angeles, California 90027 [D.W.]

\begin{abstract}
Forty-three twin lamb fetuses of $121 \pm 1 \mathrm{~d}$ gestation were catheterized and received i.v. saline $(n=8)$, $0.75 \mathrm{mg} / \mathrm{kg} / \mathrm{h}$ cortisol for $60 \mathrm{~h}(n=15), 5 \mu \mathrm{g} / \mathrm{kg}$ thyrotropin-releasing hormone (TRH) every $12 \mathrm{~h}$ for five doses ( $n$ $=9)$, or cortisol and TRH $(n=11)$ before delivery at 128 \pm 1 d. After delivery, the lambs were randomized for natural sheep surfactant treatment or sham treatment, ventilated for $75 \mathrm{~min}$, and killed. Superoxide dismutase, catalase, and glutathione peroxidase activities were measured in fetal lung tissue. Superoxide dismutase and catalase activities were increased in both the corticosteroid $(p<$ $0.001)$ and the corticosteroid with TRH $(p<0.01)$ groups. Glutathione peroxidase activity was higher after prenatal corticosteroid treatment, but statistical significance was not reached $(p=0.06)$. Although prenatal exposure to corticosteroids increased superoxide dismutase, catalase, and glutathione peroxidase activities, TRH alone or TRH added to corticosteroids provided no additional benefit. Lambs treated with surfactant had higher lung catalase activities than lambs that did not receive surfactant, probably secondary to the presence of catalase activity in the surfactant preparation. Increased pulmonary antioxidant enzyme activity may be an additional feature of the overall beneficial effect of corticosteroids on fetal lung development. (Pediatr Res 30: 518-521, 1991)
\end{abstract}

\section{Abbreviations}

GPX, glutathione peroxidase

SOD, superoxide dismutase

$\mathrm{T}_{3}$, triiodothyronine

$T_{4}$, thyroxine

TRH, thyrotropin-releasing hormone

VEI, ventilatory efficiency index

Exposure of the lung to high concentrations of oxygen produces endothelial and alveolar type I cell damage associated with alveolar-capillary leakage, lung edema, and, ultimately, deterioration of lung function. Alveolar type II cells synthesize and secrete surfactant and maintain the integrity of the alveolar epithelium by proliferation and differentiation into type I cells

Received February 11, 1991; accepted July 19, 1991.

Correspondence: Frans J. Walther, M.D., Ph.D., Division of Neonatology, Department of Pediatrics, King/Drew Medical Center, 12021 S. Wilmington Ave., Los Angeles, CA 90059.

Supported by Grant HD 20618 from the National Institutes of Health and by a grant from the Faculty Research and Innovation Fund of the University of Southern California. and are relatively resistant against oxygen toxicity secondary to a high antioxidant enzyme activity (1). The foremost intracellular antioxidant enzymes are SOD, catalase, and GPX. SOD catalyzes the dismutation of the superoxide radical, whereas catalase and GPX both sequester hydrogen peroxide formed from the dismutation reaction. At higher concentrations of hydrogen peroxide, catalase has a greater scavenging activity than GPX. Antioxidant enzyme activities increase rapidly, in parallel with phospholipid content, during the final 10 to $15 \%$ of gestation in the hamster (2), rat $(2-5)$, rabbit $(2,6)$, guinea pig $(2)$, lamb $(7,8)$, and human fetus (9). Under normoxic conditions, free oxygen radicals are kept in check by the antioxidant enzymes, but during hyperoxia production of free oxygen radicals increases rapidly and may overwhelm the capacity for detoxification. The premature infant with surfactant deficiency may be further compromised by an underdeveloped antioxidant defense system when exposed to high concentrations of oxygen. Accelerated maturation of the antioxidant enzyme system in the fetal lung may therefore be of clinical benefit.

Various hormones influence pulmonary differentiation. Corticosteroids (cortisol, dexamethasone) and thyroid hormones $\left(\mathrm{T}_{3}\right.$ and $T_{4}$ ) accelerate surfactant synthesis and have additive or synergistic effects on morphologic and biochemical development of nonventilated fetal lung (10). Ikegami et al. (11) treated pregnant rabbits with betamethasone, $\mathrm{T}_{3}, \mathrm{TRH}$ alone, or combinations of betamethasone plus $\mathrm{T}_{3}$ or TRH. Combined TRH and corticosteroid treatment significantly augmented the response of the ventilated preterm rabbit lung to surfactant replacement therapy, suggesting that TRH is an attractive agent for potential clinical use in augmenting pulmonary development, especially because it readily crosses the placenta, causing both thyroid axis stimulation and increased circulating prolactin (12, 13). Whereas corticosteroids stimulate (14), $T_{3}$ depresses antioxidant enzyme synthesis in fetal rat lung (15). Preliminary data suggest that TRH depresses antioxidant enzyme maturation in fetal rat lung (16). Because of the potential clinical usefulness of corticosteroids and TRH in ameliorating neonatal respiratory distress syndrome, we tested their effect on antioxidant enzyme activity in ventilated immature lamb lungs.

\section{MATERIALS AND METHODS}

Fetal catheterization and hormone treatments. Animals used in this study were the sheep used for lung function studies reported by Ikegami et al. (17). In brief, date-mated mixed Western breed sheep with twin pregnancies underwent hysterotomy at $121 \pm 1 \mathrm{~d}$ gestation (term is $150 \mathrm{~d}$ ). After exposure of a fetal hindlimb, arterial and venous catheters were introduced to the level of the abdominal aorta and inferior vena cava. respectively. Starting at $125 \pm 1$ d gestation, the ewes were 
randomized into four treatment groups: saline, corticosteroid, TRH, or the combination of corticosteroid and TRH. Each twin fetus received the same infusion. Eight fetuses received a continuous infusion of heparinized saline $(1 \mathrm{U} / \mathrm{mL})$ at $2 \mathrm{~mL} / \mathrm{h}$ and 5 intermittent bolus injections of normal saline $(1 \mathrm{~mL} / \mathrm{kg}$ estimated body weight) at 12 -h intervals. Fifteen fetuses received a continuous infusion of $0.75 \mathrm{mg}$ cortisol $/ \mathrm{kg}$ estimated body weight/h (Solu-Cortef; Upjohn, Kalamazoo, MI) diluted in $2 \mathrm{~mL}$ of heparinized normal saline and five intermittent bolus injections of normal saline $(1 \mathrm{~mL} / \mathrm{kg}$ estimated body weight). Nine fetuses received a continuous infusion of heparinized normal saline at $2 \mathrm{~mL} / \mathrm{h}$ and five intermittent bolus injections of $5 \mu \mathrm{g} /$ $\mathrm{kg}$ estimated fetal weight of synthetic TRH (Bachem, Torrance, CA) at 12-h intervals. Eleven fetuses received both continuous cortisol infusion $(0.75 \mathrm{mg} / \mathrm{kg} / \mathrm{h})$ and intermittent bolus injections of TRH $(5 \mu \mathrm{g} / \mathrm{kg}$ every $12 \mathrm{~h})$. All infusions were given i.v. until delivery.

Postnatal studies. At $128 \pm 1 \mathrm{~d}$ gestation, after $60 \mathrm{~h}$ of cortisol or saline infusion and $7 \mathrm{~h}$ after the 5 th TRH or saline injection, fetuses were delivered by cesarean section. An endotracheal tube was inserted, and one of each pair of twin lambs was randomly assigned to treatment with $50 \mathrm{mg} / \mathrm{kg}$ natural sheep surfactant and the other received sham treatment. Initial ventilator settings were: rate, 40 breaths/min; inspiratory time, $0.7 \mathrm{~s}$; positive endexpiratory pressure, $3 \mathrm{~cm} \mathrm{H}_{2} \mathrm{O}$; and $100 \%$ oxygen. An umbilical artery catheter was placed in the thoracic aorta, and ventilation was stabilized by adjustments in peak inspiratory pressures. Subsequently, only the peak inspiratory pressure was altered to maintain $\mathrm{PCO}_{2}$ values between 4.0 and $5.3 \mathrm{kPa}$. Core body temperature was maintained with radiant heaters and heating lamps. At $15 \mathrm{~min}$ of age, each animal was given $5 \mu \mathrm{Ci}{ }^{131} \mathrm{I}-$ albumin via the umbilical artery catheter (17). Dynamic compliance and VEI values were obtained during ventilation (18). The VEI formula equals $3800: \Delta \mathrm{P} \cdot \mathrm{f} \cdot \mathrm{PCO}_{2}$, where 3800 is a constant relating to $\mathrm{CO}_{2}$ production $\left(\mathrm{mL} \cdot \mathrm{kPa} \cdot \mathrm{kg}^{-1} \cdot \mathrm{min}\right), \Delta \mathrm{P}$ is the difference between peak inspiratory and positive end-expiratory pressure, $\mathrm{f}$ is the ventilatory frequency, and $\mathrm{PCO}_{2}$ is the arteria $\mathrm{CO}_{2}$ pressure in $\mathrm{kPa}$. After 75 min of ventilation, blood was collected for $\mathrm{Hb}$ measurements and the lambs were killed. The lungs were removed and weighed. A pressure-volume curve was made, and the lungs were lavaged six times with cold saline. The lung tissue was homogenized in $500 \mathrm{~mL}$ normal saline and centrifuged at $15000 \times g$ for $10 \mathrm{~min}$ at $4^{\circ} \mathrm{C}$. The supernatant was used for antioxidant enzyme assays and DNA content. Hb concentrations were determined in lung homogenates and blood and used to correct the amount of ${ }^{131}$ I-albumin (19) and antioxidant enzyme activities (20) contributed by intravascular blood.

Antioxidant enzyme activities and DNA. Total SOD activity was assayed by inhibition of the reduction of cytochrome $c$ in the xanthine oxidase reaction (21) using a modification described by Forman and Fisher (1). Endogenous reductants in the samples, which could interfere with the assay by producing nonsuperoxide-dependent cytochrome $c$ reduction, were eliminated by mixing the sample and $5 \times 10^{-5} \mathrm{M}$ cytochrome $c$ in $0.6 \mathrm{~mL}$ of $0.5 \mathrm{M}$ potassium phosphate buffer, $\mathrm{pH} 7.8$, and allowing the reduction and reoxidation by endogenous cytochrome oxidase of the cytochrome $c$ to occur. The reaction was followed at 550 $\mathrm{nm}$ in a DU-7 spectrophotometer (Beckman Instruments, Inc., Fullerton, CA). After incubation in the small volume, $10^{-5} \mathrm{M}$ cyanide was added to inhibit cytochrome oxidase, followed by xanthine, xanthine oxidase, and $\mathrm{H}_{2} \mathrm{O}$ to a final volume of $3 \mathrm{~mL}$. One unit of SOD equaled $50 \%$ inhibition of cytochrome $c$ reduction.

Catalase activity was measured by the rate of reduction of hydrogen peroxide substrate, followed spectrophotometrically at $240 \mathrm{~nm}$ (22). One unit of catalase equals $1 \mu \mathrm{mol}$ hydrogen peroxide decomposed $/ \mathrm{min}$ at $25^{\circ} \mathrm{C}$.

GPX activity was assayed spectrophotometrically at $340 \mathrm{~nm}$ by the rate of oxidation of NADPH (23). The assay mixture for measurement of this cytosolic enzyme includes cumene hydro- peroxide as primary substrate, with sodium azide added to inhibit contributing activity from catalase enzyme.

The DNA content of the tissue samples was determined by the fluorimetric method of Erwin et al. (24).

Statistical methods. Results of antioxidant enzyme analyses are expressed as units of enzyme activity per mg DNA and are presented as mean \pm SEM. Comparisons between antioxidant enzyme activities at various experimental conditions were done using analysis of variance and correlations between antioxidant enzyme activities and VEI, compliance, and protein leak measurements by regression analysis.

\section{RESULTS}

Mean weight of the 43 lambs was $2.33 \pm 0.05 \mathrm{~kg}$ and mean lung weight was $92.7 \pm 2.5 \mathrm{~g} ; 23$ were males. Three fetuses, one in each hormone treatment group, with cord $\mathrm{pH}$ values less than 7.0 died and were excluded from the data analysis. Twenty lambs were treated with natural sheep surfactant at birth. Both serum $\mathrm{T}_{3}$ and $\mathrm{T}_{4}$ levels increased after TRH administration. In addition, corticosteroid treatment slightly increased serum $T_{3}$ levels in non-TRH-treated animals. Hormone values in plasma samples obtained before hormone treatment and in umbilical cord plasma samples before surfactant administration are reported elsewhere (17).

Figure 1 presents the mean \pm SEM SOD, catalase, and GPX
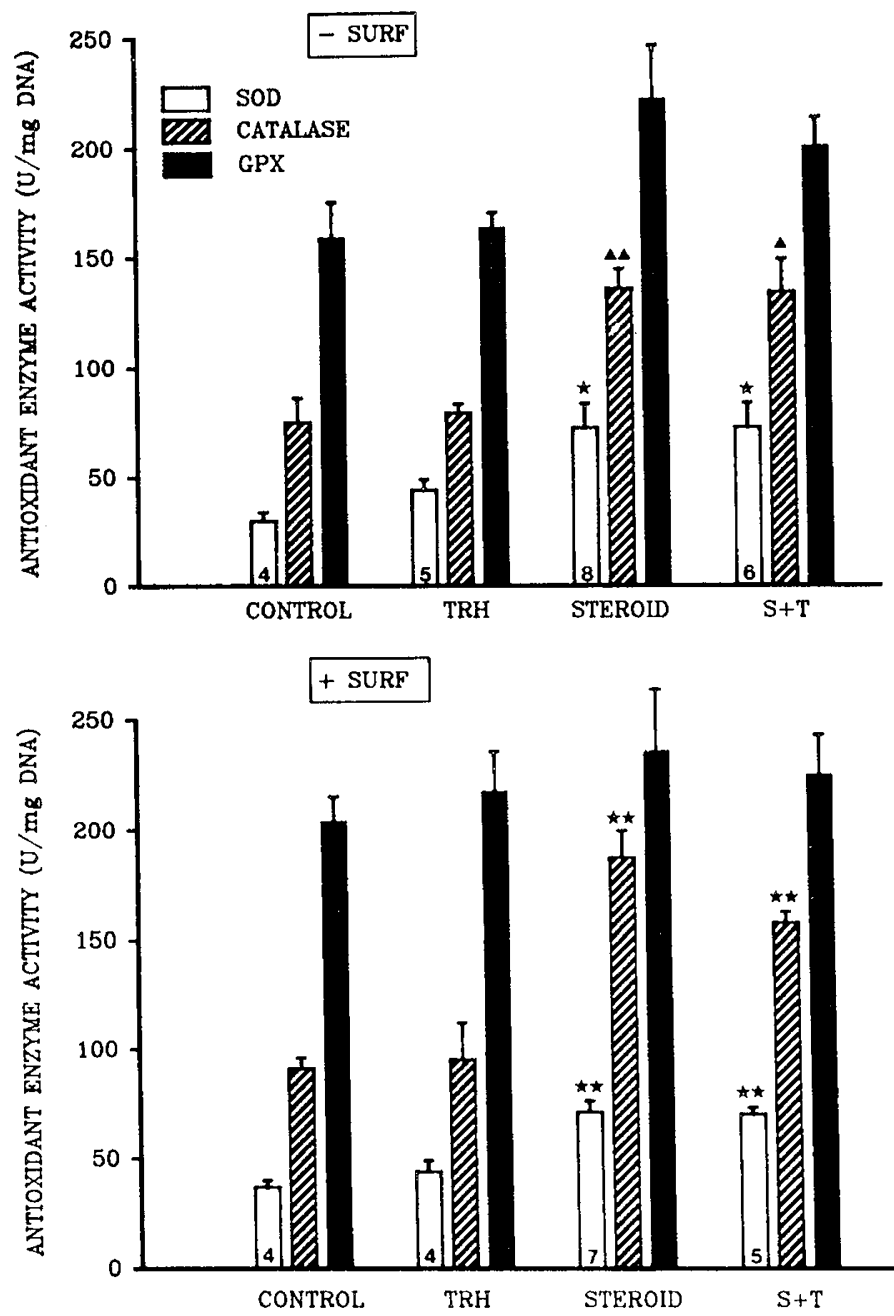

Fig. 1. SOD, catalase, and GPX activity in fetal lamb lung after prenatal administration of saline, steroid, TRH, or steroid and TRH $(S+T)$ and postnatal surfactant $(+S U R F)$ or sham treatment $(-S U R F)$. Numbers indicate the number of animals in each experimental group. *, $p<0.01 ; \boldsymbol{\Lambda}, p<0.02 ; \boldsymbol{\Lambda \Lambda}, p<0.005 ;{ }^{* *}, p<0.001$ versus control. 
values in the saline controls and the TRH, corticosteroid, and corticosteroid and TRH groups subdivided by surfactant treatment status. Although pulmonary antioxidant enzyme activities tended to be higher in subgroups treated with surfactant than in subgroups that did not receive surfactant, these differences were significant only for catalase activity in the corticosteroid group $(p<0.005)$. Corticosteroid treatment significantly increased lung SOD and catalase activity, irrespective of surfactant treatment, but TRH treatment did not affect activity of either enzyme. GPX values varied considerably within each group and tended to increase after prenatal treatment with corticosteroids, but not with TRH. Comparison of the antioxidant enzyme activities between the two groups that received corticosteroids and the two groups that did not receive corticosteroids confirmed these findings. In the corticosteroid group, SOD activity was $68 \pm 6$ versus $40 \pm 3 \mathrm{U} / \mathrm{mg}$ DNA in the noncorticosteroid group $(F$ ratio $=$ $14.129, p<0.001)$, catalase activity was $145 \pm 8$ versus $85 \pm 5$ $\mathrm{U} / \mathrm{mg}$ DNA $(F$ ratio $=28.702, p<0.001)$, and GPX activity was $221 \pm 12$ versus $187 \pm 10 \mathrm{U} / \mathrm{mg}$ DNA $(p=0.06)$.

Compliance, VEI measures, and ${ }^{131}$ I-albumin accumulation in the lungs correlated with catalase activity, but not with SOD or GPX activities. With increasing catalase activity, compliance and VEI improved $(r=0.50, p<0.001$ and $r=0.46, p=0.002$, respectively) (Fig. 2), whereas the accumulation of intravascular ${ }^{131}$ I-albumin in the total lung (lung tissue plus alveolar wash) and in the alveolar lavage alone decreased significantly $(r=0.66$ and 0.68 , respectively; $p<0.001$ for both) (Fig. 3). These effects also correlated with surfactant treatment (Figs. 2 and 3).

Catalase activity in the surfactant preparation was $20.26 \pm$ $0.49 \mathrm{U} / \mathrm{mg}$ surfactant lipid $(n=6)$; SOD and GPX activities were not detected. This suggests that the increase in lung tissue catalase activity in surfactant-treated lambs compared with con-
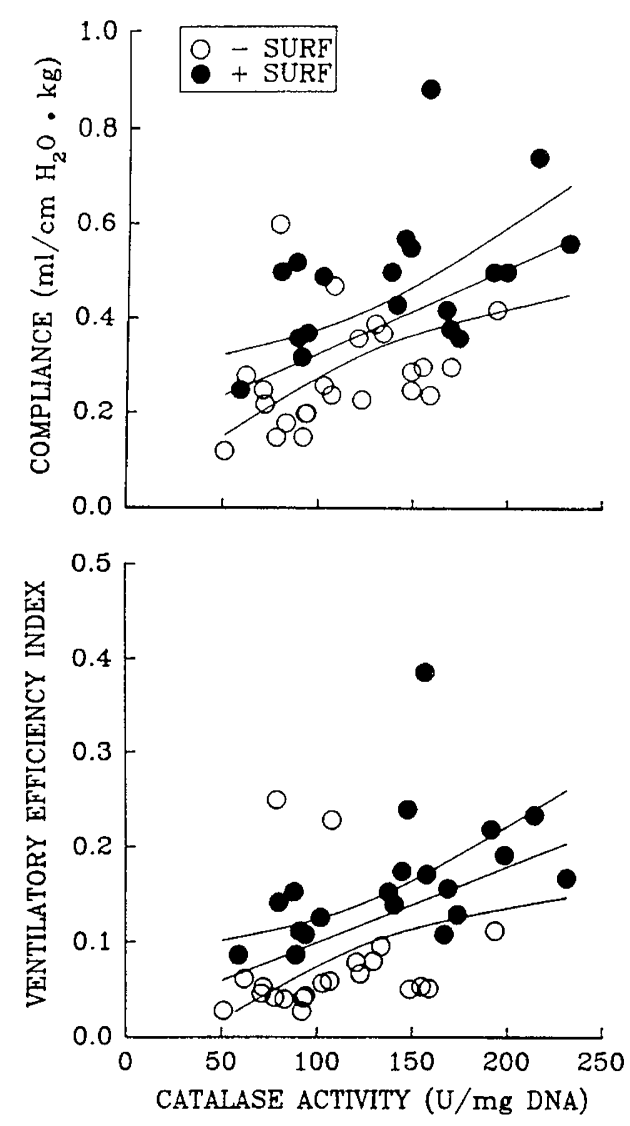

Fig. 2. Compliance and VEI values, calculated from the average values at 35,55 , and $75 \mathrm{~min}$ for each animal, versus lung catalase activity for surfactant- $(\bullet)$ and sham-treated $(O)$ animals (compliance: $r=0.50$, $p<0.001$; VEI: $r=0.46, p=0.002$; and $95 \%$ confidence limits).
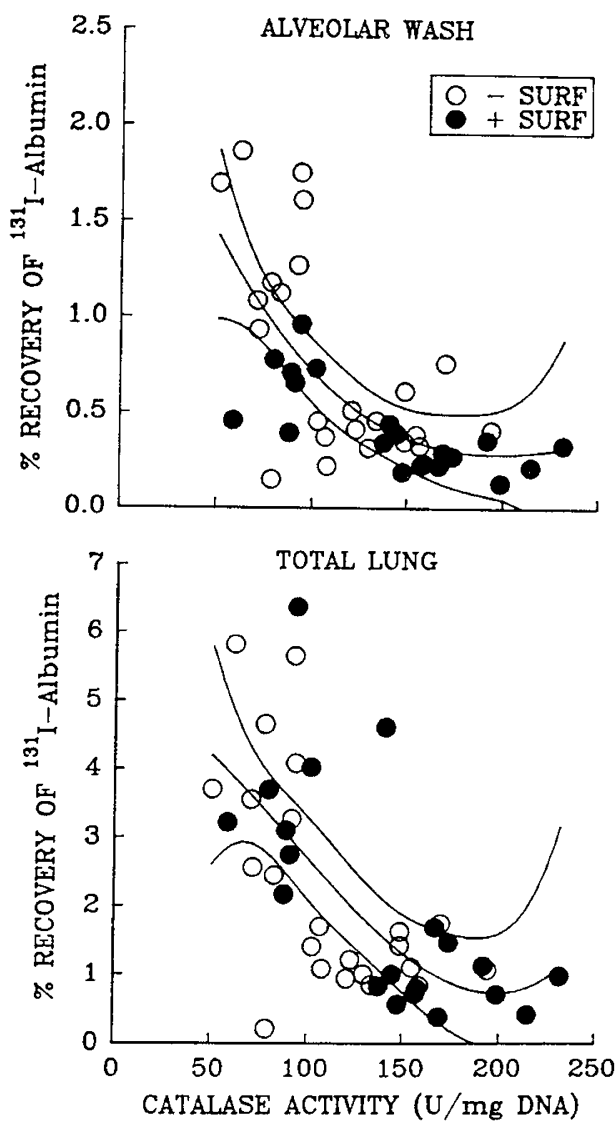

Fig. 3. Percentage of recovery of intravascularly administered ${ }^{131}$ Ialbumin by alveolar wash and in the total lung (lung tissue plus alveolar wash) versus lung catalase activity for surfactant- $(\bullet)$ and sham-treated (O) animals (alveolar wash: $r=0.68, p<0.001$; total lung: $r=0.66, p<$ $0.001 ; 95 \%$ confidence limits).

trols is secondary to an average uptake of $29.9 \%$ of the catalase present in the surfactant preparation.

\section{DISCUSSION}

The focus of these experiments was to evaluate lung antioxidant enzyme activity in preterm lambs after fetal hormone and surfactant treatments given at doses and for durations comparable to those that have been used clinically.

Corticosteroids alone considerably improved lung function measurements: compliance increased, gas exchange as indicated by the ventilation index improved, maximal lung volumes and volumes at low transpulmonary pressures increased as measured from pressure-volume curves, and the movement of labeled albumin into and out of the lungs as a measurement of the tendency to develop pulmonary edema decreased (17). Surfactant pool sizes were not affected by corticosteroids. Results with TRH alone were not different from the controls, and no significant additive effects of combined corticosteroid and TRH therapy on postnatal lung function or alveolar saturated phosphatidylcholine pools were seen (17).

Baseline values of pulmonary antioxidant enzyme activities in the preterm lambs in the present study were comparable to values obtained previously in fetal sheep of similar gestational age (8) and indicate that $75 \mathrm{~min}$ of mechanical ventilation with $100 \%$ oxygen after birth by cesarean section did not influence antioxidant enzyme activity. Similarly, although surfactant administration at birth was associated with higher arterial $\mathrm{PO}_{2}$ levels, antioxidant enzyme activity was not affected, at least for periods up to $75 \mathrm{~min}$. Prenatal corticosteroid administration increased the activities of SOD, catalase, and GPX in fetal lamb lung, but the latter failed to reach statistical significance. TRH 
alone or in addition to corticosteroids did not provide additional benefits in pulmonary antioxidant enzyme activity, nor did it decrease levels of activity. Lung catalase activity was higher in lambs treated with natural sheep surfactant at birth. Natural lung surfactants contain measurable amounts of SOD and catalase activities and can increase antioxidant enzyme content in alveolar epithelial cells (25). The surfactant preparation used in this study contained catalase activity, whereas SOD and GPX activities were below detectable levels. Liposome encapsulation of catalase permits uptake by alveolar type II cells in vitro and renders them more resistant to oxidant stress with hydrogen peroxide (26). The presence of catalase in the surfactant preparation may therefore explain the higher catalase activity in surfactant-treated lungs, especially because the percentage of exogenous catalase associated with lung tissue was similar to the percentage of exogenous surfactant phospholipids associated with lung tissue.

A combination of corticosteroids and thyroid hormones improves lung function in fetal rabbits (11) and in fetal sheep (10, 27). Dexamethasone given to pregnant rats during late gestation accelerates the increase of the activities of pulmonary SOD, catalase, and GPX (14), whereas adrenocortical blockade in fetal rats with metyrapone, an 11- $\beta$-steroid hydroxylase inhibitor, reduces both surfactant content and pulmonary antioxidant enzyme activities (28). In rat fetal lung cell cultures, dexamethasone increases SOD and GPX activities, but not catalase activity (29, 30 ). Whether this change in antioxidant enzyme activity is a direct effect of corticosteroids on alveolar type II cells or, as is the case for surfactant lipids, is largely mediated through induction of fibroblast-pneumonocyte factor (31) is unclear. Pulmonary SOD activity is lower in hypothyroid fetal lambs and returns to normal after $T_{4}$ administration (7). However, injection of pregnant rats with $\mathrm{T}_{3}$ depresses pulmonary SOD, catalase, and GPX activities in the fetus (15). Fetal offspring from methimazole- and propylthiouracil-treated hypothyroid pregnant rats have increased pulmonary antioxidant enzyme activities (32). The present study confirms that pulmonary SOD, catalase, and GPX activities increase secondary to prenatal corticosteroid administration, but are not affected by prenatal TRH treatment. Estimation of antioxidant enzyme synthesis may provide additional information concerning enzyme responsitivity.

The correlation between catalase activity and protein leakage, an indicator of lung injury, was an unexpected finding, especially within the context of a much weaker correlation between catalase activity and compliance and VEI. The observation by Ikegami et al. (17) that prenatal corticosteroids improve lung function measures without changing surfactant pool sizes and our finding that corticosteroids induce an increase in catalase activity raise the issue of cause and effect. The induction of lung catalase activity by corticosteroids and the catalase activity of natural surfactant both have the potential to reduce pulmonary oxygen toxicity. Whether increased catalase activity affects lung function measures after only 75 min of mechanical ventilation, when lung injury is probably minimal, remains an issue that needs further study.

Acknowledgment. The authors thank Alma B. Wade for technical assistance.

\section{REFERENCES}

1. Forman HJ, Fisher AB 1981 Antioxidant enzymes of rat granular pneumocytes. Constitutive levels and effect of hyperoxia. Lab Invest 45:1-6

2. Frank L, Sosenko IRS 1987 Prenatal development of lung antioxidant enzymes in four species. J Pediatr 110:106-110

3. Yam J, Frank L, Roberts RJ 1978 Age-related development of pulmonary antioxidant enzymes in the rat. Proc Soc Exp Biol Med 157:293-296

4. Tanswell AK, Freeman BA 1984 Pulmonary antioxidant enzyme maturation in the fetal and neonatal rat. I. Developmental profiles. Pediatr Res 18:584587

5. Gerdin E, Tyden O, Eriksson UJ 1985 The development of antioxidant enzymatic defense in the perinatal rat lung: activities of superoxide dismutase, glutathione peroxidase, and catalase. Pediatr Res 19:687-691

6. Frank L, Groseclose EE 1984 Preparation for birth into an $\mathrm{O}_{2}$-rich environment: the antioxidant enzymes in the developing rabbit lung. Pediatr Res $18: 240-244$

7. Erenberg A, Frank L, Roberts RJ, Rhodes ML 1982 Pulmonary superoxide dismutase activity in the euthyroid and hypothyroid ovine fetus. Pediatr Res 16:570-572

8. Walther FJ, Wade AB, Warburton D, Forman HJ 1991 Ontogeny of antioxidant enzymes in the fetal lamb lung. Exp Lung Res 17:39-45

9. Autor AP, Frank L, Roberts RJ 1976 Developmental characteristics of pulmonary superoxide dismutase: relationship to idiopathic respiratory distress syndrome. Pediatr Res 10:154-158

10. Warburton D, Parton L, Buckley S, Cosico L, Enns G, Saluna T 1988 Combined effects of corticosteroid, thyroid hormones, and B-agonist on surfactant, pulmonary mechanics, and B-receptor binding in fetal lamb lung. Pediatr Res 24:166-170

11. Ikegami M, Jobe AH, Pettenazzo A, Seidner SR, Berry DD, Buffini L 1987 Effects of maternal treatment with corticosteroids, $\mathrm{T}_{3}, \mathrm{TRH}$, and their combinations on lung function of ventilated preterm rabbits with and without surfactant treatments. Am Rev Respir Dis 136:892-898

12. Liggins GC, Schellenberg JC 1986 Hormones and lung maturation. In: Johnston BM, Gluckman PD (eds) Reproductive and Perinatal Medicine. III Respiratory Control and Lung Development in the Fetus and Newborn. Perinatology Press, New York, pp 107-133

13. Rooney SA, Marino PA, Gobran LI, Gross I, Warshaw JB 1979 Thyrotropinreleasing hormone increases the amount of surfactant in lung lavage from fetal rabbits. Pediatr Res 13:623-625

14. Frank L, Lewis PL, Sosenko IRS 1985 Dexamethasone stimulation of fetal rat lung antioxidant enzyme activity in parallel with surfactant stimulation. Pediatrics 75:569-574

15. Sosenko IRS, Frank L 1987 Thyroid hormone depresses antioxidant enzyme maturation in fetal rat lung. Am J Physiol 253:R592-R598

16. Antigua MCB, Sosenko IRS, Frank L 1989 Thyrotropin releasing hormone (TRH) depresses antioxidant enzyme maturation in fetal rat lung. Pediatr Res 25:46A(abstr)

17. Ikegami M, Polk D, Tabor B, Lewis J, Yamada T, Jobe A 1991 Corticosteroid and thyrotropin-releasing hormone effects on preterm sheep lung function. J Appl Physiol 70:2268-2278

18. Notter RH, Egan EA, Kwong MS, Holm BA, Shapiro DL 1985 Lung surfactant replacement in premature lambs with extracted lipid from bovine lung lavage: effects of dose, dispersion technique and gestational age. Pediatr Res 19:569-577

19. Jobe A, Ikegami M, Harris J, Jones S, Conaway D 1983 Permeability of premature lamb lungs to protein and the effect of surfactant on that permeability. J Appl Physiol 55:169-176

20. Cross CE, Watanabe TT, Hasegawa GK, Goralnik GN, Roertgen KE, Kaizu T, Reiser KM, Gorin AB, Last JA 1979 Biochemical assays in lung homogenates: artifacts caused by trapped blood after perfusion. Toxicol Appl Pharmacol 48:99-109

21. McCord JM, Fridovich I 1969 Superoxide dismutase: an enzymatic function for erythrocuprein (Hemocuprein). J Biol Chem 244:6049-6055

22. Holmes RS, Masters CJ 1970 Epigenetic interconversions of the multiple forms of mouse liver catalase. FEBS Lett 11:45-48

23. Paglia DE, Valentine WN 1967 Studies on the quantitative and qualitative characterization of erythrocyte glutathione peroxidase. J Lab Clin Med 70:158-169

24. Erwin BG, Stoschek CM, Florini JR 1981 A rapid fluorimetric method for the estimation of DNA in cultured cells. Anal Biochem 110:291-294

25. Matalon S, Holm BA, Baker RR, Whitfield MK, Freeman BA 1990 Characterization of antioxidant activities of pulmonary surfactant mixtures. Biochim Biophys Acta 1035:121-127

26. Buckley BJ, Tanswell AK, Freeman BA 1987 Liposome-mediated augmentation of catalase in alveolar type II cells protects against $\mathrm{H}_{2} \mathrm{O}_{2}$ injury. J Appl Physiol 63:359-367

27. Schellenberg J-C, Liggins GC, Manzai M, Kitterman JA, Lee CCH 1988 Synergistic hormonal effects on lung maturation in fetal sheep. J Appl Physiol 65:94-100

28. Sosenko IRS, Lewis PL, Frank L 1986 Metyrapone delays surfactant and antioxidant enzyme maturation in developing rat lung. Pediatr Res 20:672675

29. Randhawa P, Hass M, Frank L, Massaro D 1986 Dexamethasone increases superoxide dismutase activity in serum-free rat lung organ cultures. Pediatr Res 20:895-898

30. Tanswell AK, Tzaki MG, Byrne PJ 1986 Hormonal and local factors influence antioxidant enzyme activity of rat fetal lung cells in vitro. Exp Lung Res 11:49-59

31. Smith BT, Sabry K 1983 Glucocorticoid-thyroid synergism in lung maturation: a mechanism involving epithelial-mesenchymal interaction. Proc Natl Acad Sci USA 80:1951-1954

32. Sosenko IRS, Frank L 1989 Thyroid inhibition and developmental increases in fetal rat lung antioxidant enzymes. Am J Physiol 257:L94-L99 